\title{
Kinase activity and subcellular distribution of a chimeric green fluorescent protein-tagged Janus kinase 2
}

\author{
Sheeyong Lee \& Roy J. Duhé* \\ Department of Pharmacology and Toxicology, University of Mississippi Medical Center, 2500 North State St, \\ Jackson, MS, 39216, USA
}

Received 12 June 2006; accepted 9 August 2006

(C) 2006 National Science Council, Taipei

Key words: autokinase activity, enhanced green fluorescent protein (EGFP), Janus kinase 2 (JAK2), subcellular localization

\begin{abstract}
Summary
Janus kinase 2 (JAK2) is an essential intracellular signal transducer for numerous cytokines and hormones. To examine how JAK2 structural modifications can affect cellular physiology, we created expression vectors for chimeric proteins containing an enhanced green fluorescent protein (EGFP) fused to rat JAK2 (EGFP/rJAK2), and a kinase-inactive variant, EGFP/rJAK2(K882E). The properties of EGFP/rJAK2 were examined following transient transfection of COS-7 cells. EGFP/rJAK2 was expressed throughout the cell, and was found in subcellular membrane, cytosolic and nuclear fractions. Interestingly, EGFP/rJAK2 phosphorylated other proteins in situ without additional cytokine stimulation. Furthermore, despite a much higher level of tyrosine phosphorylation arising from in situ autophosphorylation, the in vitro radiolabelling autokinase activity of EGFP/rJAK2 was significantly less than that of the endogenous JAK2. These results reveal a technical limitation of the application of the "conventional" in vitro radiolabelling autokinase assay to hyperphosphorylated forms of the enzyme and illustrate the potential weaknesses in individual assays commonly used to determine JAK2's enzymatic activity and subcellular distribution. We also suggest that the EGFP/rJAK2 model can be very useful in studying JAK2-related cancers, because its ubiquitous distribution and abnormal constitutive hyperphosphorylation may distinguish it from the cytokine-regulated, membrane-proximal form of JAK2 associated with normal physiology.
\end{abstract}

\section{Introduction}

Janus kinase 2 (JAK2) $[1,2]$ is a member of the Janus protein-tyrosine kinase (JAK) family [3]. Other JAKs found within the phylum Chordata include JAK1 [4], JAK3 [5, 6], and TYK2 [7]. Because the JAKs are integral to many aspects of developmental biology and immunology, mutations and regulatory aberrations can have devastating consequences. Several human cancers are associated with constitutive activation of JAK2. Genomic amplification of JAK2 has been observed in Hodg-

*To whom correspondence should be addressed. E-mail: RDUHE@pharmacology.umsmed.edu kin's lymphoma [8]. Constitutive activation of JAK2 can arise from overexpression [9], from loss of feedback regulation [10], and from chromosomal translocations that displace JAK2's autoinhibitory domain $[11,12]$. However, it is improbable that many human diseases arise from congenital systemic inactivation of JAK 2 because in transgenic animal models, animals lacking jak2 die in utero due to the inability to progress from primitive to definitive hematopoiesis $[13,14]$. There might be other as-yetunrecognized pathologies associated with JAK2 deficiencies in somatic cells, although the nature of such pathologies would be highly speculative.

Despite the broad importance of JAK2, it is still an imperfectly understood enzyme. Surprisingly, 
even fundamental questions concerning JAK2's subcellular distribution have yet to be resolved in an unambiguous fashion. Because the purified enzyme appears to indiscriminately phosphorylate a variety of substrates [15], the subcellular localization of the endogenous enzyme would appear to represent an important mechanism for controlling substrate access under physiological conditions. While it is conventional wisdom that JAK2 phosphorylates STATs and other substrates associated with cytokine receptors, one could envision dramatically altered consequences if JAK2 were to directly phosphorylate substrates found within other organelles, such as the nucleus. Some investigators have provided evidence that yellow fluorescent protein-chimeras containing JAK1, JAK2 or TYK 2 are predominantly located at the cellular membrane [16, 17]. On the other hand, other groups, whose investigations did not employ fluorescent chimeras, reported a nucleocytoplasmic distribution for JAK2 [18-20], while yet other investigators reported that hemagglutinin-tagged JAK2 was distributed in the cytoplasm but excluded from the nucleus [21]. In order to further examine these and other issues surrounding the properties of JAK2's catalytic properties in a cellular context, we sought to develop other approaches to produce the recombinant enzyme in various mammalian cells. To exploit the advantages of fluorescent chimeras in our planned JAK2 structure/function studies, we built an enhanced green fluorescent protein-tagged rat JAK2 protein (EGFP/rJAK2), along with a kinase-inactive $\mathrm{EGFP} / \mathrm{rJAK} 2$ (K882E) variant as a negative control. The enhanced green fluorescent protein (EGFP) was selected for this chimeric protein design because its bright fluorescence easily allows one to track the intracellular localization of the fusion protein in living cells [22].

\section{Materials and methods}

Construction of pEGFP:rJAK2 and pEGFP:rJAK2(K882E) expression vectors

The chimeric pEGFP:rJAK2 expression vector was built in two steps. First, a cDNA fragment encoding the first 295 amino acid residues of rat JAK2 was generated via polymerase chain reaction (PCR) using the plasmid pRA3.17 [23] as a template, and 5'ATATAAGTACTCAATGG GAATGGCTTGCCTTACAAT3' and 5'TTGA CCACTGAATTCCACCGTTTCCAGTTAT-

$\mathrm{TA}^{\prime}$ as the reaction primers. The resultant $0.9 \mathrm{~kb}$ PCR product was subcloned into the ScaI/EcoRI site of the pEGFP-C3 vector (Clontech), yielding the plasmid pEGFP:rJAK2(C $\Delta 295)$. In the second step, a $3 \mathrm{~kb}$ EcoRI fragment encoding the remaining carboxyl terminal of rJAK2 was isolated from pRA3.17, then subcloned into pEGFP:rJAK2(CA295) to yield pEGFP:rJAK2, the structure of which was verified by DNA sequencing. The kinase-inactive pEGFP:rJAK2 (K882E) expression vector was derived from the pEFGP:rJAK2 via QuikCHANGE ${ }^{\mathrm{TM}}$ (Stratagene) site-directed mutagenesis using the primers 5'GAGGTGGTAGCTGTTGAGAAGCTCCAG CACAG3' and 5'CTGTGCTGGAGCTTCTCAACAGCTACCACCTC3'. The mutation was confirmed by DNA sequence analysis.

\section{Cell culture and transfection}

COS-7 cells (American Type Culture Collection) were maintained in humidified $5 \% \mathrm{CO}_{2}$ at $37{ }^{\circ} \mathrm{C}$ in Dulbecco's modified Eagle's medium (Invitrogen) supplemented with L-glutamine, penicillin/streptomycin and 10\% heat-inactivated fetal bovine serum (Atlanta Biologicals). COS-7 cells, seeded at a density of $1 \times 10^{6}$ per $100 \mathrm{~mm}$ dish, were transiently transfected with $6 \mu \mathrm{g}$ of plasmid DNA using Effectene ${ }^{\mathrm{TM}}$ transfection reagent (Qiagen) according to the manufacturer's instruction. The transfected cells were incubated for 24-72 $\mathrm{h}$ before conducting various assays. In case of epifluorescence analysis with 4',6-diamidino-2-phenylindole (DAPI) counterstaining, $2 \times 10^{4}$ cells were seeded onto glass cover slips in a 24-well cell culture dish one day before transfection and cells were transiently transfected with $1 \mu \mathrm{g}$ of plasmid DNA per well.

\section{Microscopic and flow cytometry analysis}

Three days after transfection, adherent cells were recovered by treatment with sterile trypsin-EDTA (ethylenediamine tetraacetate) solution (Sigma), then washed with phosphate-buffered saline (PBS). After washing, the cells were resuspended in PBS and analyzed for fluorescence intensity by flow cytometry using a fluorescence activated cell 
sorting (FACS) system (BD Biosciences FACScan system). Fluorescence photomicroscopy was performed using a Leica DM IRB inverted fluorescence microscope equipped with an Optronics MagnaFire digital camera and a filter optimized for GFP fluorescence (480 $\mathrm{nm}$ excitation (Ex.) and $535 \mathrm{~nm}$ emission with $40 \mathrm{~nm}$ and $50 \mathrm{~nm}$ respective bandwidths). For epifluorescence analysis with DAPI staining, cells were collected 2 days after transfection, rinsed twice with PBS and fixed by adding $1 \mathrm{ml}$ of $4 \%$ paraformaldehyde for $20 \mathrm{~min}$. The cells were washed twice with PBS and stained with $1 \mathrm{nM}$ DAPI for $10 \mathrm{~min}$. The cells on the cover slip were rinsed twice with PBS and mounted on a glass slide and sealed. The cells were observed through an epifluorescence microscope (Nikon EFD-3) at $60 \times$ magnification with a filter (UV2 A, Nikon) (Ex. 330-380 nm, DM $400 \mathrm{~nm}, \mathrm{BA}$ $420 \mathrm{~nm}$ ) for DAPI staining and another filter (FITC-HVQ, Nikon) (Ex. 460-500 nm, DM $505 \mathrm{~nm}$, BA $510-560 \mathrm{~nm}$ ) for EGFP and EGFP-chimera proteins.

\section{Immunoprecipitation, SDS-PAGE and Western blot assays}

Three days after transfection, $1 \times 10^{7}$ transfected cells were recovered, then lysed in a lysis buffer [24] containing $1 \%$ Triton X-100, $5 \mathrm{mM}$ EDTA, $50 \mathrm{mM} \mathrm{NaCl}, 30 \mathrm{mM}$ sodium diphosphate, $50 \mathrm{mM} \mathrm{NaF}, 0.2 \mathrm{mM}$ sodium orthovanadate, $1 \mathrm{mM}$ phenylmethylsulfonyl fluoride (PMSF), $5 \mu \mathrm{g} / \mathrm{ml}$ aprotinin, $1 \mu \mathrm{g} / \mathrm{ml}$ pepstatin $\mathrm{A}, 2 \mu \mathrm{g} / \mathrm{ml}$ leupeptin, and $10 \mathrm{mM}$ Tris- $\mathrm{Cl}, \mathrm{pH}$ 7.6. After centrifugation $\left(8500 \times g\right.$ for $15 \mathrm{~min}$ at $\left.4{ }^{\circ} \mathrm{C}\right)$, the clarified cell lysates were incubated with antiJAK2 antibodies (cat. \# 06-255, Upstate Cell Signaling Solutions) for $3 \mathrm{~h}$ at $4{ }^{\circ} \mathrm{C}$ with mixing, then one-tenth volume of $10 \%$ protein-A Sepharose $^{\mathrm{TM}} \mathrm{CL}-4 \mathrm{~B}$ (Amersham Biosciences) was added and mixed for $2 \mathrm{~h}$ at $4{ }^{\circ} \mathrm{C}$. The samples were centrifuged at $7000 \times g$ for $10 \mathrm{~min}$ at $4{ }^{\circ} \mathrm{C}$ to pellet the immobilized JAK2/antibody complexes, which were washed three times with lysis buffer. The sample was divided into two equal aliquots, one of which was analyzed by Western blot and the other was analyzed by in vitro radiolabelling autokinase assay, as previously described [25]. For the Western blot analysis, the immunoprecipitated materials were resolved by $7.5 \%$ sodium dodecyl sulfate-polyacrylamide gel electrophoresis
(SDS-PAGE), then transferred to Immobilon-P transfer membranes (Millipore). The membranes were probed with either anti-JAK2, anti-phosphotyrosine (4G10, cat. \# 05-321, Upstate Cell Signaling Solutions) or anti-GFP antibody (cat. \# 8367-1, Clontech), thrice washed, re-blocked, probed with appropriate secondary antibodies, and thrice washed again. The immunoreactive proteins were detected using the enhanced chemiluminescence system (ECL, Amersham Biosciences). For reprobing with a different antibody, previously probed membrane was incubated with buffer containing $100 \mathrm{mM} \beta$-mercaptoethanol, $2 \%$ SDS, and $62.5 \mathrm{mM}$ Tris- $\mathrm{Cl}$ (pH 6.7) for $30 \mathrm{~min}$ at $50{ }^{\circ} \mathrm{C}$. After being washed and blocked, the membrane was reprobed and processed as described above.

\section{In vitro radiolabelling autokinase assay}

The samples were prepared as described in the "Immunoprecipitation, SDS-PAGE and Western blot assays" section. The second half of the immunoprecipitated pellet was pre-treated with $10 \mathrm{mM}$ dithiothreitol (DTT) to maximize enzyme activity [25], resuspended with $100 \mu \mathrm{l}$ of autokinase cocktail solution $(250 \mu \mathrm{Ci} / \mathrm{ml}$ carrier-free $\left[\gamma^{32} \mathrm{P}\right] \mathrm{ATP}, 50 \mathrm{mM} \mathrm{NaCl}, 5 \mathrm{mM} \mathrm{MgCl}_{2}, 5 \mathrm{mM}$ $\mathrm{MnCl}_{2}, \quad 0.1 \mathrm{mM} \quad \mathrm{Na}_{3} \mathrm{VO}_{4}, \quad 10 \mathrm{mM}$ HEPES, $\mathrm{pH}$ 7.6) and incubated at room temperature for 20 min with mixing. The reactions were stopped by centrifuging briefly, discarding the cocktail solution and washing the pellets three times with lysis buffer. The samples were then boiled with SDS-PAGE sample buffer for $3 \mathrm{~min}$, and resolved by $7.5 \%$ SDS-PAGE. The gel was transblotted onto Immobilon-P transfer membranes and Coomassie stained; radiolabel incorporation was quantified via PhosphorImager analysis (Molecular Dynamics) [15].

\section{Subcellular fractionation}

Cell fractions were prepared as previously described by Behrmann et al. [16]. In brief, 2 days after transfection, $5 \times 10^{6}$ cells were harvested and resuspended in $1 \mathrm{ml}$ of hypotonic lysis buffer $(10 \mathrm{mM} \mathrm{NaCl}, 3 \mathrm{mM} \mathrm{MgCl}, 1 \mathrm{mM}$ sodium vanadate, $5 \mu \mathrm{g} / \mathrm{ml}$ aprotinin, $3 \mu \mathrm{g} / \mathrm{ml}$ pepstatin, $5 \mu \mathrm{g} / \mathrm{ml}$ leupeptin, $1 \mathrm{mM}$ EDTA, $1 \mathrm{mM}$ DTT, and $10 \mathrm{mM}$ Tris-Cl, $\mathrm{pH}$ 7.5). After homogenation 
using a Dounce homogenizer, the nuclei were separated by centrifugation $(35 \times g, 15 \mathrm{~min}$, twice), yielding the crude nuclear pellet. Centrifugation of this supernatant at $12,500 \times g$ for $15 \mathrm{~min}$ generated another supernatant (the crude cytoplasmic fraction) and pellet (the crude plasma membrane fraction). The crude cytoplasmic fraction was further centrifuged for $1 \mathrm{~h}$ at $100,000 \times g$ to yield the pure cytoplasmic fraction. The crude membrane pellet was resuspended and lysed in $1 \mathrm{ml}$ of $1 \%$ Triton lysis buffer $(1 \%$ Triton X-100, $120 \mathrm{mM} \mathrm{NaCl}, 10 \mathrm{mM} \mathrm{NaF}, 1 \mathrm{mM}$ sodium vanadate, $5 \mu \mathrm{g} / \mathrm{ml}$ aprotinin, $3 \mu \mathrm{g} / \mathrm{ml}$ pepstatin, $5 \mu \mathrm{g} / \mathrm{ml}$ leupeptin, $1 \mathrm{mM}$ EDTA, $1 \mathrm{mM}$ DTT, and $20 \mathrm{mM}$ Tris-Cl, $\mathrm{pH}$ 7.5). After 30-min incubation, the lysate was centrifuged at $12,500 \times g$ for $15 \mathrm{~min}$ to remove insoluble material and the supernatant was used as the pure membrane fraction. Nuclear fractions were prepared as described by Buckley et al. [26] with a slight modification. The crude nuclear pellet was resuspended in $1 \mathrm{ml}$ of nuclear isolation buffer $(0.5 \%$ Nonidet P- $40,10 \mathrm{mM}$ $\mathrm{NaCl}, 3 \mathrm{mM} \mathrm{MgCl}_{2}, 1 \mathrm{mM}$ sodium vanadate, $5 \mu \mathrm{g} / \mathrm{ml}$ aprotinin, $3 \mu \mathrm{g} / \mathrm{ml}$ pepstatin, $5 \mu \mathrm{g} / \mathrm{ml}$ leupeptin, $1 \mathrm{mM}$ EDTA, $1 \mathrm{mM}$ DTT, and $10 \mathrm{mM}$ Tris-Cl, $\mathrm{pH} 7.5$ ), incubated on ice for $5 \mathrm{~min}$, then centrifuged at $35 \times \mathrm{g}$ twice. The pellet was washed with $1 \mathrm{ml}$ of $2 \%$ Triton-containing nuclear lysis buffer $(2 \%$ Triton X-100, $280 \mathrm{mM}$ $\mathrm{NaCl}, 10 \mathrm{mM} \mathrm{NaF}, 1 \mathrm{mM}$ sodium vanadate, $5 \mu \mathrm{g} /$ $\mathrm{ml}$ aprotinin, $3 \mu \mathrm{g} / \mathrm{ml}$ pepstatin, $5 \mu \mathrm{g} / \mathrm{ml}$ leupeptin, $1 \mathrm{mM}$ EDTA, $1 \mathrm{mM}$ DTT, and $20 \mathrm{mM}$ Tris-Cl, $\mathrm{pH}$ 7.5), and centrifuged at $12,500 \times g$ for $10 \mathrm{~min}$. The purified nuclear pellet was solubilized in $200 \mu \mathrm{l}$ of SDS-PAGE sample buffer.

\section{Western blot assay for subcellular fractions}

Fifty microliters of each fraction $(50 \mu 1$ from $1 \mathrm{ml}$ of membrane fraction, $50 \mu \mathrm{l}$ from $1 \mathrm{ml}$ of cystosol fraction, and $50 \mu \mathrm{l}$ from $200 \mu \mathrm{l}$ of nuclear fraction) were electrophoresed via SDS-PAGE prior to Western blot assay. The proteins were transferred to Immobilon-P transfer membranes and probed with the following antibodies: anti-JAK2, antilamin A/C (cat. \# 636, Santa Cruz Biotechnology), anti-calnexin (cat. \# 610523, Transduction Laboratories), anti-phosphotyrosine, anti-GFP, and anti-phospho-JAK2 (pTyr-1007,1008; cat. \# 07123, Upstate Cell Signaling Solutions). Proteins were visualized using the ECL system.

\section{Statistical analysis}

To compare the relative fluorescence intensity of chimeric protein expressing cells, one way ANOVA and Student-Newman-Keuls post-hoc test were used. Significance was defined as $p<0.05$.

All experiments were repeated at least three times and representative images are shown.

\section{Results}

Microscopic examination of COS-7 cells producing recombinant EGFP, EGFP/rJAK2, and EGFP/ rJAK2(K882E) proteins

We created expression vectors for an enhanced green fluorescent protein chimera in which the fluorescent protein was fused to the amino-terminus of rat JAK2 (EGFP/rJAK2), along with a kinase-inactive control protein (EGFP/ rJAK2(K882E)) [27, 28]. Following transient transfection, all three fluorescent chimeric proteins were produced in COS-7 cells and the characteristic green fluorescence was observed microscopically for all recombinant proteins (Figure 1). The fluorescence appeared to be uniformly distributed throughout the cells for all three constructs and cells could be found with uniform patterns that did not appear to vary according to the nature of the chimera. We also observed that COS-7 cells producing either EGFP/rJAK2 or EGFP/ rJAK2(K882E) were less bright than COS-7 cells producing non-chimeric EGFP. Furthermore, the fluorescent cells which expressed recombinant JAK 2 contracted into a non-viable spheroid which ultimately detached from the surface of the culture dish. We were unsuccessful in attempts to establish stably transfected COS-7 cells or CHO-K1 cells producing either EGFP/rJAK2 or EGFP/ rJAK2(K882E) using G418 drug selection and physical isolation by ring cloning, although we were able to isolate apparently stable clonal cells lines producing the non-chimeric EGFP (data not shown).

To examine subcellular distribution, the transiently transfected COS-7 cells were fixed, counterstained with DAPI to reveal nuclei, then examined at $60 \times$ magnification using an upright epifluorescence microscope (Nikon EFD-3). Consistently, the EGFP/rJAK2 was ubiquitously distributed 


\section{EGFP}

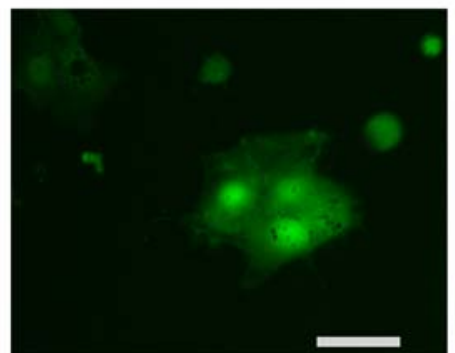

DAY 1

DAY 2

DAY 3
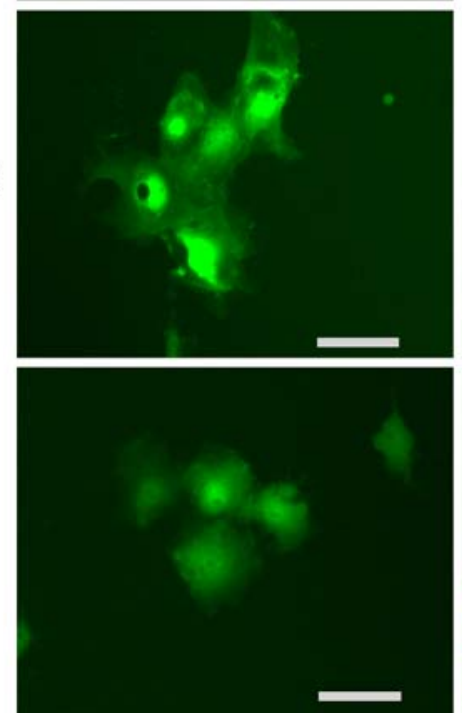

EGFP/rJAK2
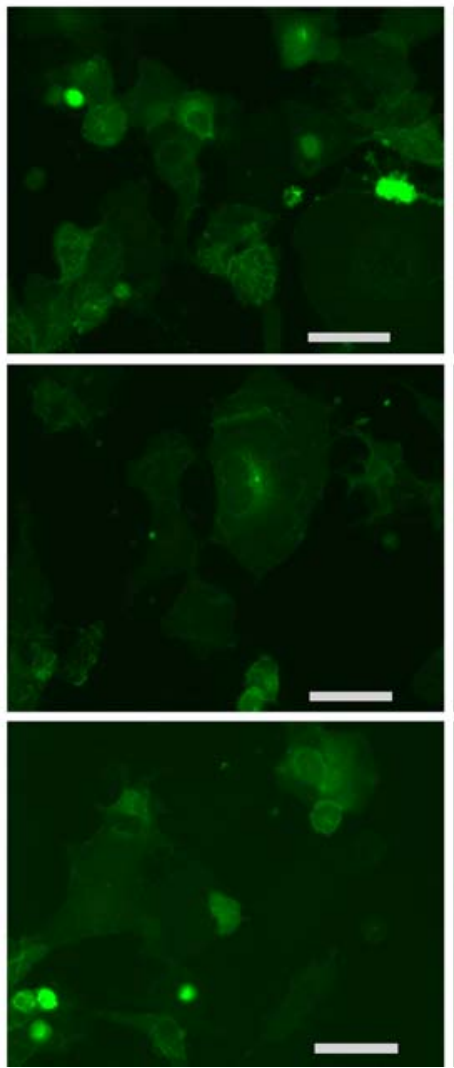

EGFP/rJAK2

(K882E)
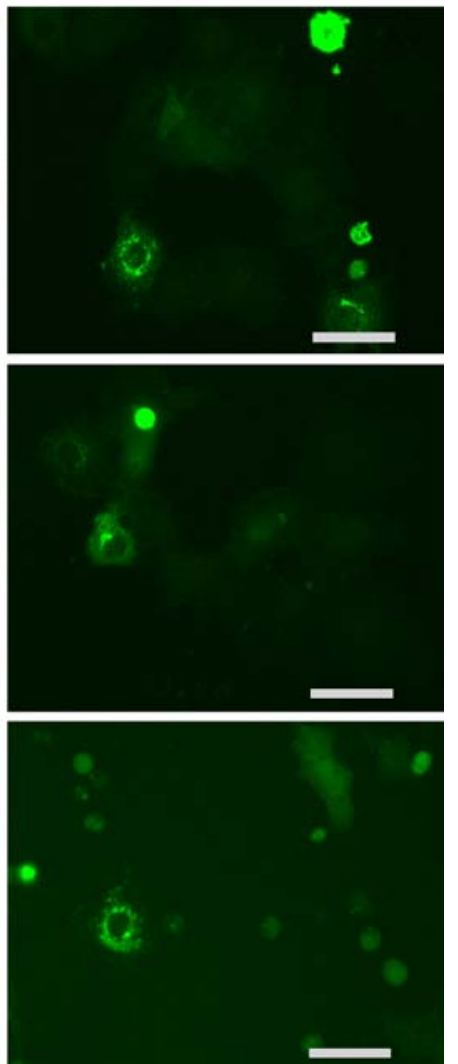

Figure 1. Fluorescent images of EGFP and EGFP-fused JAK2 proteins expressed in COS-7 cells. COS-7 cells were transfected with each of the three expression vectors, as described in the "Materials and methods" section. Cells were observed daily after transfection (day 0) and images were obtained using a $20 \times$ objective and a $480 \mathrm{~nm}$ excitation/535 nm emission filter set optimized for the green fluorescent proteins. Bar $=50 \mu \mathrm{m}$.

throughout the transfected COS-7 cells, as was the case with the non-tagged EGFP (Figure 2). Interestingly, EGFP/rJAK2(K882E) was excluded from the nucleus in some cells, as shown in an example in Figure 2 (pattern A), but was uniformly distributed in other transfected cells in the same experiments (pattern B).

\section{Subcellular fractionation of transfected COS-7 cells}

pEGFP:rJAK2 transfected COS-7 cells were carefully lysed and prepared for subcellular fractionation. Sham-transfected COS-7 cells were also prepared as a control. The lysed cells were fractionated as described under the "Materials and methods" section and the fractionated samples were resolved via SDS-PAGE, transferred to membranes and analyzed by Western blot. To ensure that the purified membrane, cytosolic and nuclear fractions were not contaminated by each other, the membranes were probed with antibodies for calnexin, a membrane fraction marker [29, 30], and for lamins $\mathrm{A}$ and $\mathrm{C}$, which are nuclear marker proteins $[31,32]$. The membranes were stripped, then re-probed with antibodies recognizing JAK2, GFP, phosphotyrosine or phospho-JAK2. The results are shown in Figure 3.

The combined presence of lamins A and C only in the nuclear fractions (Figure 3, panel F, lanes 3 and 6) and of calnexin only in the membrane fractions (Figure 3, panel E, lanes 1 and 4) indicates that the three subcellular fractions were adequately purified. The detection of a common $158 \mathrm{kDa}$ protein by antibodies recognizing JAK2 
DAPI

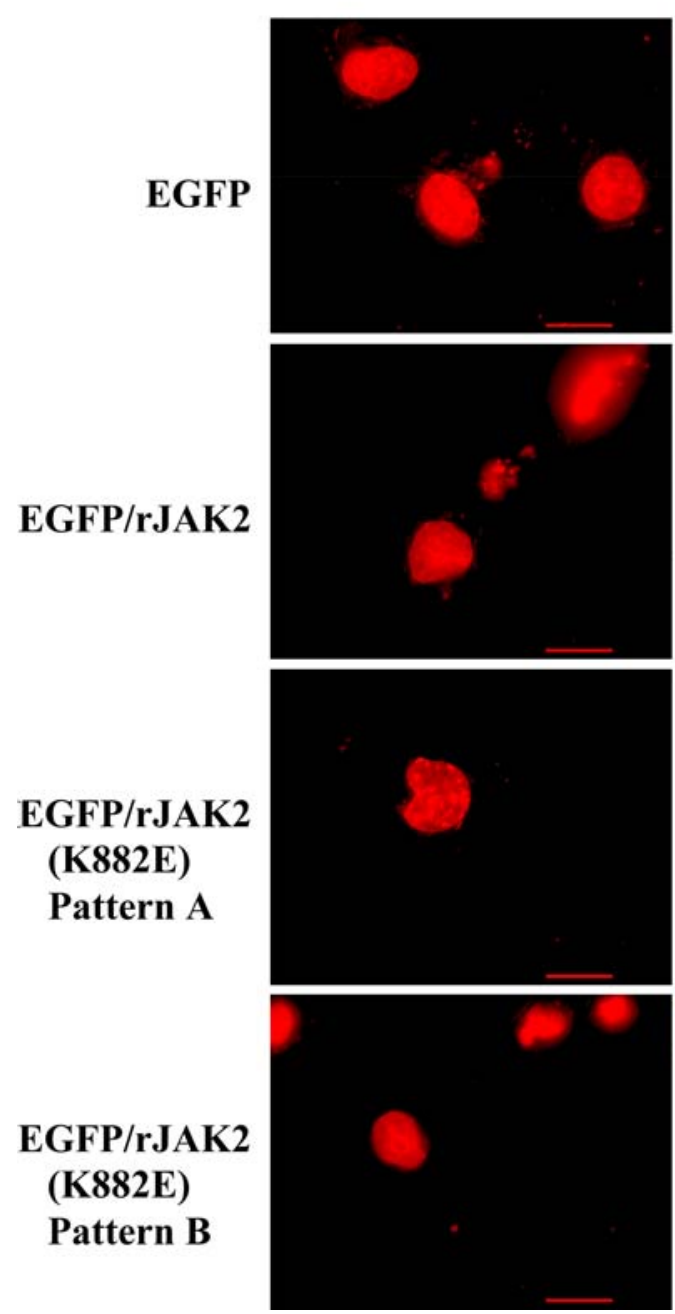

GFP
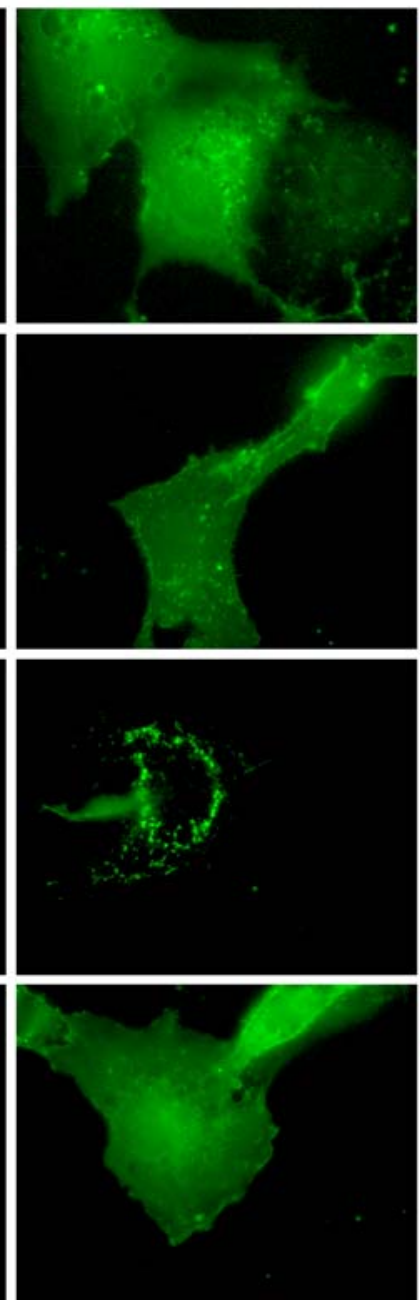

merged
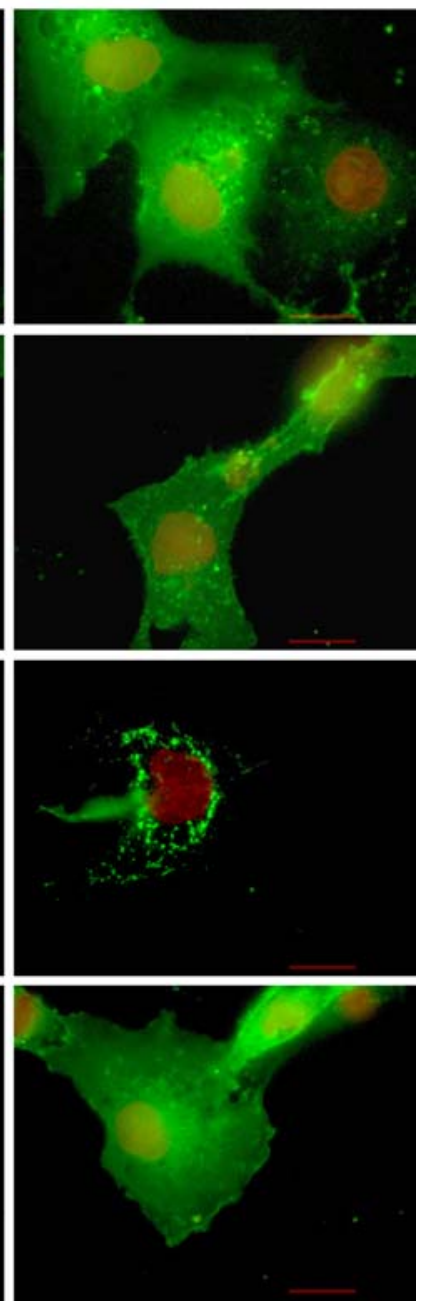

Figure 2. Epifluorescence microscopic analysis with DAPI counterstaining. Two days after transfection, COS-7 cells producing EGFP, EGFP/rJAK2, and EGFP/rJAK2(K882E) were fixed and counterstained with DAPI (1 nM). DAPI counterstaining was pseudo-colored red. Cells were observed at $60 \times$ magnification. Bar $=20 \mu \mathrm{m}$.

(Figure 3, panel A, lanes 4, 5 and 6) and GFP (Figure 3, panel B, lanes 4, 5 and 6) shows that the EGFP/rJAK2 chimera was clearly present in all compartments including membrane fraction, cytosol fraction and nuclear fraction. Further, the $\mathrm{EGFP} / \mathrm{rJAK} 2$ proteins in all compartments contained phosphorylated tyrosine residues (Figure 3, panel C, lanes 4, 5 and 6), which included tyrosine phosphorylation within the activation loop (Figure 3, panel $\mathrm{D}$, lanes 4,5 and 6). The nuclear population of EGFP/rJAK2 apparently contained a greater proportion of phosphotyrosine than the other two populations, but this has not yet been verified by alternative methodologies. In this experiment, the endogenous JAK2 was most clearly detected in the cytosol and nuclear fractions (Figure 3, panel A, lanes 2, 3, 5 and 6).

We also compared the subcellular distribution of EGFP/rJAK2 in pEGFP:rJAK2-transfected COS-7 cells with that of the inactive kinase in pEGFP:rJAK2(K882E)-transfected COS-7 cells (Figure 4). Again, the fraction markers indicated that the three subcellular fractions were appropriately purified (panel $\mathrm{E}$ and $\mathrm{F}$ ). The detection of a common $158 \mathrm{kDa}$ protein by anti-JAK2 antibody and anti-GFP antibody showed that EGFP/ rJAK2 proteins (Figure 4, panel $\mathrm{A}$ and $\mathrm{B}$, lanes 1, 2 and 3) and EGFP/rJAK2(K882E) proteins 


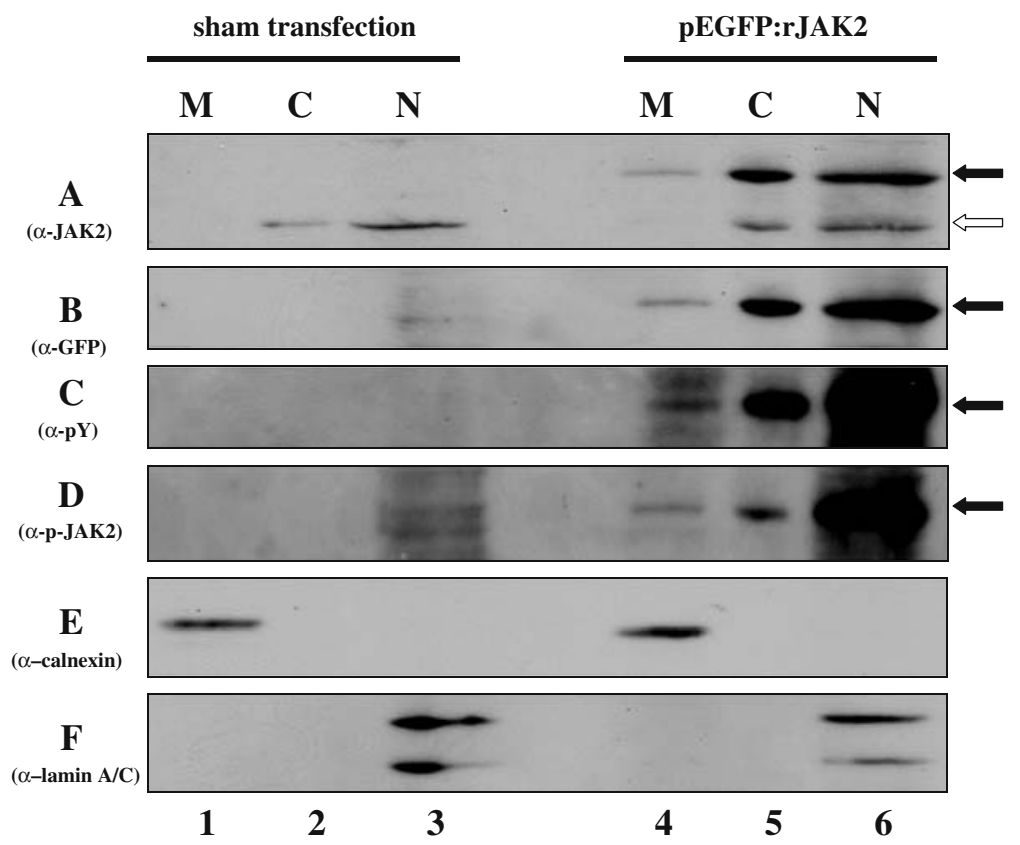

Figure 3. Western blot assay of subcellular fractions of sham-and pEGFP:rJAK2-transfected COS-7 cells. Cells were processed as described in the "Materials and methods" section to yield membrane fractions ("M", lanes 1 and 4), cytosol fractions ("C", lanes 2 and 5) and nuclear fractions ("N", lanes 3 and 6). Following resolution via SDS-PAGE and transfer to membranes, the samples were assayed for epitopes recognized by antibodies specific for JAK2 ( $\alpha$-JAK2: panel A), GFP ( $\alpha$-GFP: panel B), phosphotyrosine $(\alpha$-pY: panel C), phospho-JAK2 ( $\alpha$-p-JAK2: panel D), calnexin $(\alpha$-calnexin: panel E) and lanim A/C $(\alpha$-lamin A/C: panel F). Black arrows point to EGFP/rJAK2 proteins; White arrow points to the endogenous JAK2.

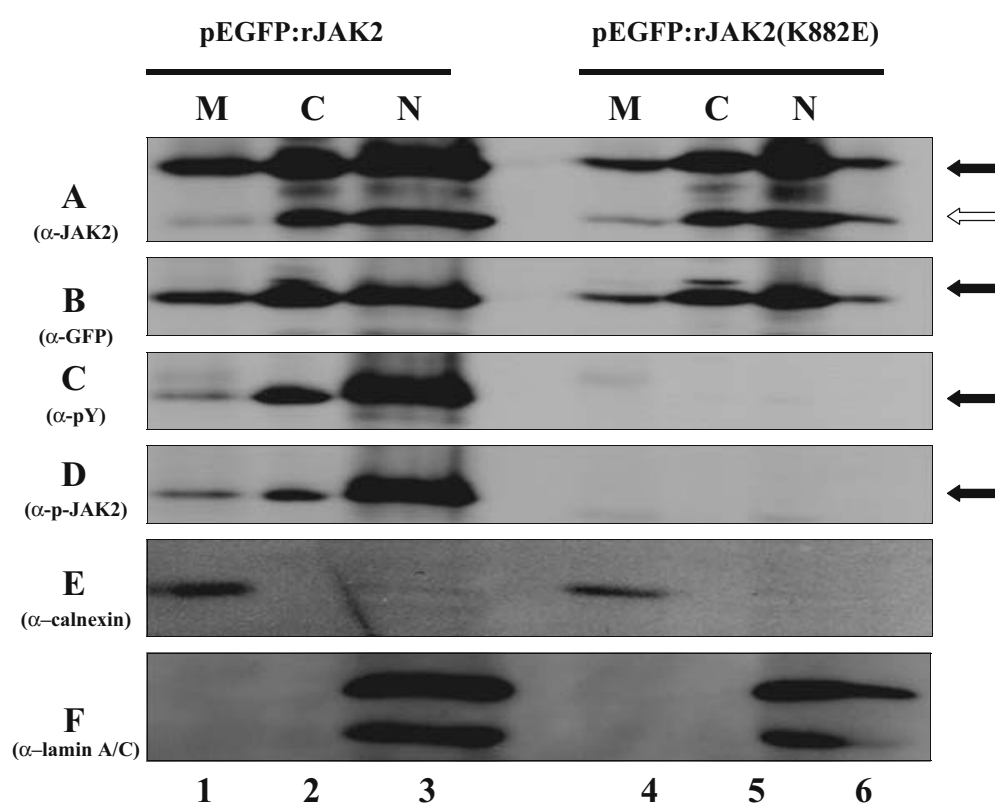

Figure 4. Western blot assay of subcellular fractions of pEGFP:rJAK2-transfected COS-7 cells and pEGFP:rJAK2(K882E)-transfected COS-7 cells. Cells were processed in the same way as described in Figure 3. Membrane fractions (M), cytosol fractions (C), and nuclear fractions $(\mathrm{N})$ were assayed via SDS-PAGE and transferred to Immobilon-P transfer membranes. The samples were assayed for epitopes recognized by antibodies specific for JAK2 (panel A), GFP (panel B), phosphotyrosine (panel C), phosphoJAK2 (panel D), calnexin (panel E) and lanim A/C (panel F). Black arrows point to EGFP/rJAK2 proteins and EGFP/ rJAK2(K882E) proteins; White arrow points to the endogenous JAK2. 
(Figure 4, panel A and B, lanes 4, 5 and 6) were present in all three subcellular fractions.

The EGFP/rJAK2 proteins in all compartments were tyrosine-phosphorylated (Figure 4, panel C, lanes 1, 2 and 3), whereas the EGFP/ rJAK2(K882E) proteins showed no sign of tyrosine phosphorylation (Figure 4, panel C, lanes 4, 5 and 6). As expected, the EGFP/rJAK2(K882E) proteins also lacked tyrosine phosphorylation within the activation loop (Figure 4, panel D, lanes 4, 5 and 6), in contrast to the EGFP/rJAK2 proteins (Figure 4, panel C, lanes 1, 2 and 3).

The results of the subcellular fractionation experiments (Figures 3 and 4) corroborated the microscopy evidence (Figures 1 and 2) indicating that the EGFP/rJAK2 is ubiquitously distributed throughout the transfected COS-7 cells. Further, the ubiquitous distribution pattern appears to be completely independent of the presence or absence of kinase activity.

\section{FACS analysis of EGFP/rJAK2 fusion proteins}

Fluorescence microscopy indicated that the fluorescence intensity of EGFP was greater than that of EGFP/rJAK2 and EGFP/rJAK2(K882E). To confirm this, we examined the fluorescence intensity of transiently transfected COS-7 cells using fluorescence activated cell sorting. Sample fluorescence distribution profiles of sham-transfected, pEGFP-transfected, pEGFP:rJAK2-transfected and pEGFP:rJAK2(K882E)-transfected COS-7 cells are shown in Figure 5, panel A. Analysis of these distribution profiles showed that there were no differences in transfection efficiency due to differences between the expression vectors. The geometric mean values of the relative fluorescence intensities of the fluorescent transfected cells are plotted in Figure 5, panel B. By applying the Student-Newman-Keuls test to ANOVA-ranked results of three separate experiments, we observed a significant difference $(p<0.05)$ in the relative fluorescence intensity of pEGFP-transfected COS-7 cells $(498 \pm 158$, as mean \pm standard deviation) in comparison to those of pEGFP:rJAK2-transfected cells $(262 \pm 21)$ and pEGFP:rJAK2(K882E)-transfected cells $(158 \pm 36)$. The presence of a JAK2 fusion partner apparently impaired the fluorescence properties of the EGFP domain. We then investigated whether the presence of the fluorescent protein may have reciprocally altered the properties of the JAK2 domain.

\section{Characteristics of the EGFP/rJAK2 chimeras produced in COS-7 cells}

Transiently transfected COS-7 cells were lysed with buffer containing nonionic detergent and the recombinant proteins were recovered via immunoprecipitation with polyclonal antibodies that recognized JAK2, which also recovered the endogenous enzyme as an internal control. The EGFP/ rJAK2 fusion proteins produced in COS-7 cells migrated under SDS-PAGE conditions as anticipated based on their predicted molecular mass of $158 \mathrm{kDa}$, and they were recognized by anti-JAK2 and anti-GFP antibodies, as shown in Figure 6, panels A and B, respectively. Densitometric analysis of the Western blots showed that EGFP/ rJAK2 and EGFP/rJAK2(K882E) were produced at approximately equal levels.

However, Western blot analysis using antiphosphotyrosine antibodies revealed a dramatic difference in the tyrosine phosphorylation status of these chimeric proteins. EGFP/rJAK2 alone exhibited significant tyrosine phosphorylation and the tyrosine phosphorylation did not require explicit cytokine receptor stimulation (Figure 6, panel C). The lack of tyrosine phosphorylation of the kinase-inactive EGFP/rJAK2(K882E) chimera provides support for the interpretation that the phosphorylation of tyrosines in EGFP/rJAK2 arose from an autophosphorylation event, rather than due to a trans-phosphorylation by another protein-tyrosine kinase present in COS-7 cells. We did not detect any significant level of phosphotyrosine in the endogenous JAK2 protein.

Aliquots of the anti-JAK2 immunoprecipitated material were then subjected to in vitro radiolabelling autokinase assays, which provide a basic measure of JAK2's enzymatic activity [33-35]. No detectable activity was associated with the kinaseinactive $\mathrm{EGFP} / \mathrm{rJAK} 2(\mathrm{~K} 882 \mathrm{E})$, as anticipated. While EGFP/rJAK2 exhibited autokinase activity, it was very low in comparison to that of the endogenous JAK2 (Figure 6, panel D). When the autokinase signal intensities were normalized to those of the JAK2-cross-reactive signals (Figure 6, panel A), the autokinase activity of EGFP/rJAK2 was only $0.7 \%$ of the normalized autokinase activity of the endogenous JAK2. 

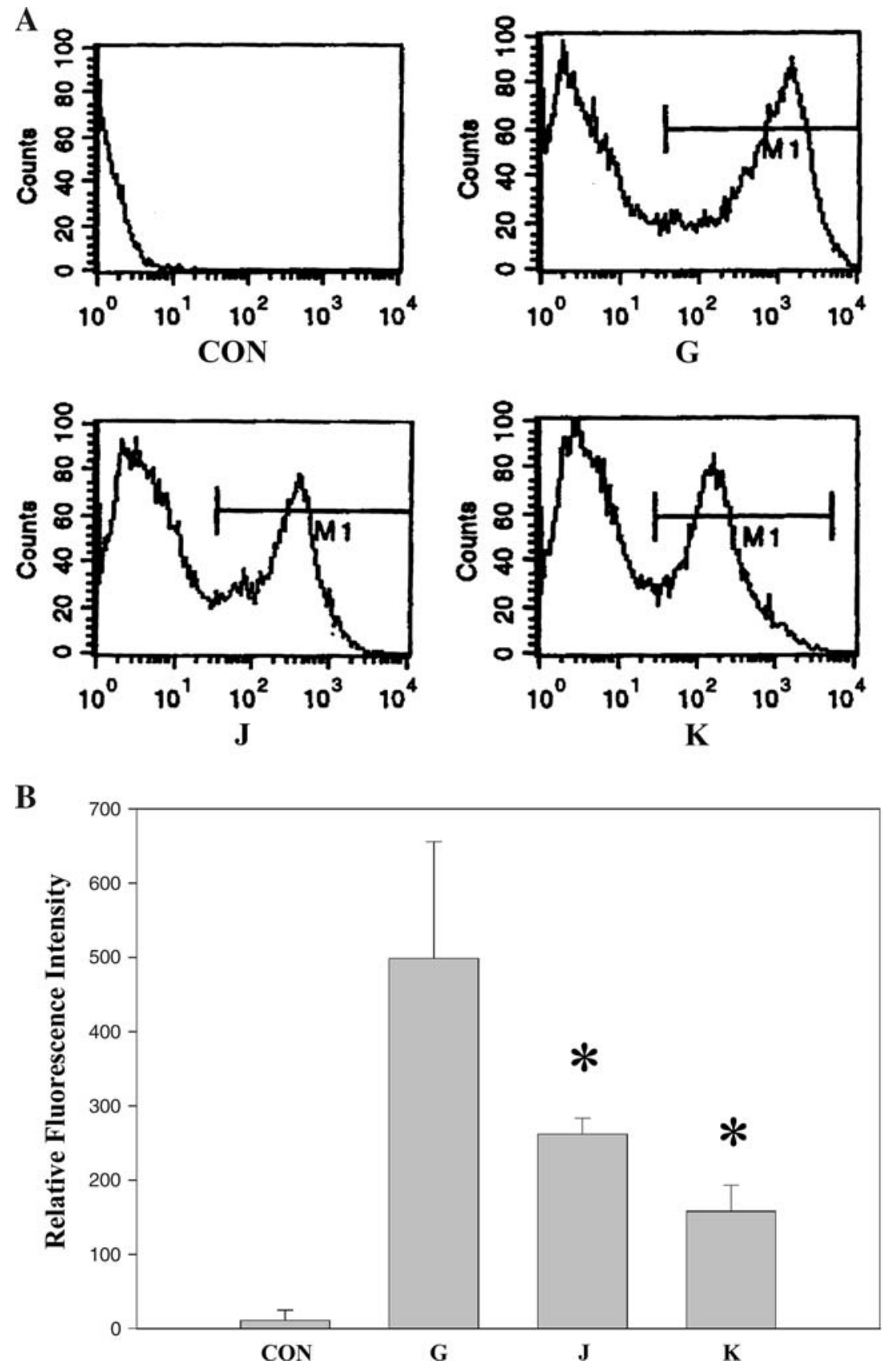

Figure 5. FACS analysis of COS-7 cells producing fluorescent proteins. Panel A: Relative fluorescence intensity distribution profiles of transiently-transfected COS-7 cells. $X$-axis: relative fluorescence intensity in logarithmic scale; $Y$-axis: cell counts. $\mathrm{CON}=$ sham-transfected COS-7 cells; $\mathrm{G}=$ pEGFP-transfected COS-7 cells; $\mathrm{J}=$ pEGFP:rJAK2-transfected COS-7 cells; $\mathrm{K}=$ pEGFP:rJAK2(K882E)-transfected COS-7 cells. Panel B: Geometric mean values of relative fluorescence intensities collected over three separate experiments. Error bars represent standard deviation. ${ }^{*} p<0.05$ (G vs. J and G vs. K).

In order to verify that EGFP/rJAK2 could transphosphorylate other cellular components, as one would expect of a functional kinase, we analyzed the phosphotyrosine content of the transfected cell lysates. As shown (Figure 7, panel A, lane J), the crude lysate from COS-7 cells producing EGFP/rJAK2 contained a broad range of tyrosine-phosphorylated proteins that were not 

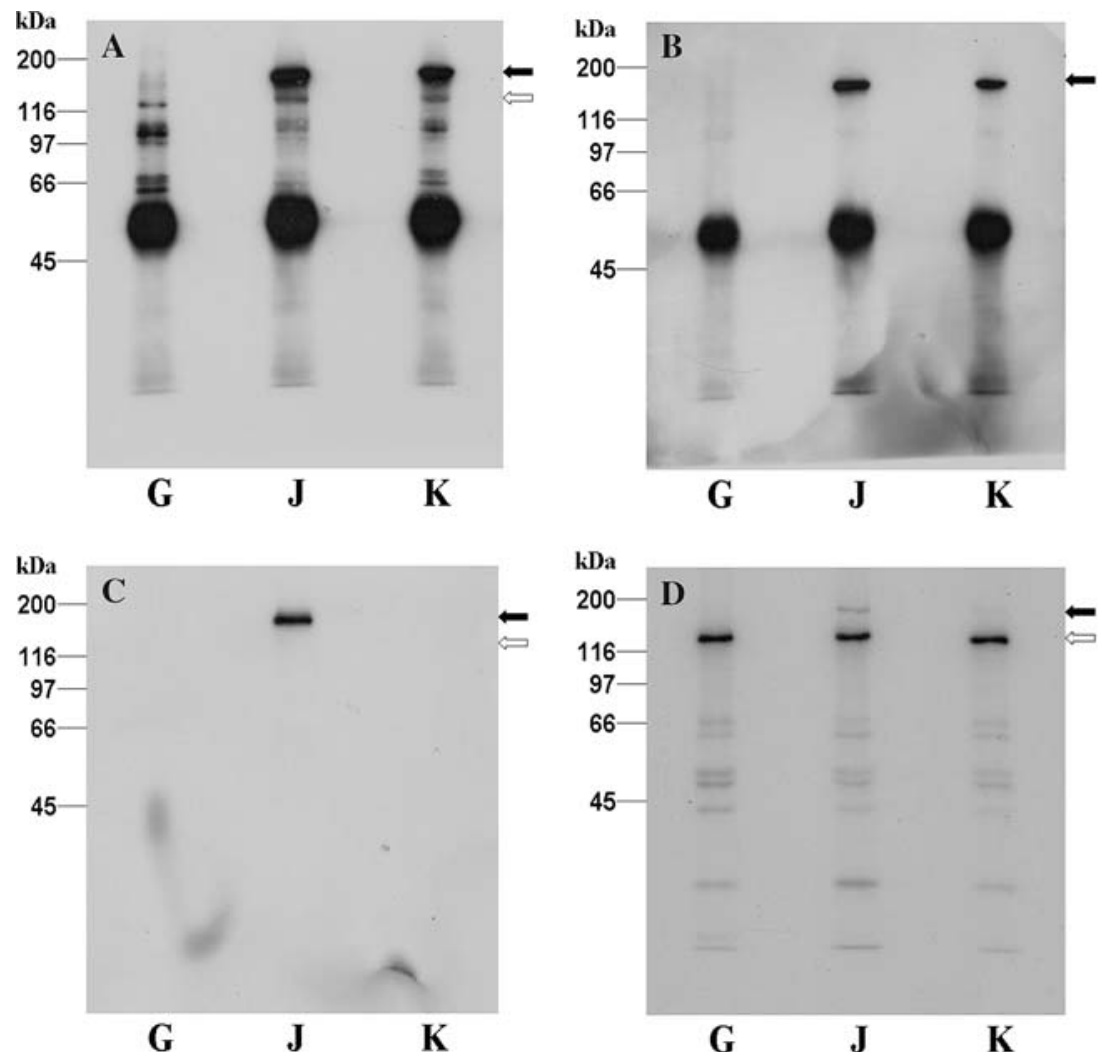

Figure 6. Characteristics of recombinant EGFP/rJAK2 and endogenous JAK2 proteins. Panel A: Western blot (WB) analysis of immunoprecipitated (IP) proteins produced in transiently transfected COS-7 cells using anti-JAK2 antibody, as described in "Materials and Methods". (IP: $\alpha$-JAK2, WB: $\alpha$-JAK2). G = pEGFP-transfectants; J = pEGFP:rJAK2-transfectants; K = pEGFP:rJAK2(K882E)-transfectants. Numbers on left side of panels indicate molecular weight standards (kDa). Black arrows point to recombinant chimeric proteins; White arrows point to the endogenous JAK2. Panel B: Western blot analysis using anti-GFP antibody. The membrane used in panel A was "stripped", then re-probed with antibody that recognizes GFP. (WB: $\alpha$-GFP). Panel C: Western blot analysis using anti-phosphotyrosine antibody. The membrane used in panel B was "stripped", then reprobed with monoclonal antibody that recognizes phosphotyrosine. (WB: $\alpha-p Y$ ). Panel D: In vitro radiolabelling autokinase assay of immunoprecipitated recombinant chimeric and endogenous JAK2 proteins, as described in "Materials and methods". (IP: $\alpha$-JAK2, then in vitro radiolabelling autokinase assay was performed).

tyrosine-phosphorylated in the lysates of either sham-transfected COS-7 cells (lane CON), EGFPproducing cells (lane $\mathrm{G}$ ) or EGFP/rJAK2(K882E)producing cells (lane $\mathrm{K}$ ). Coomassie Blue R-250 staining demonstrated that the amounts of protein and the gross distribution of proteins were approximately equal in all four samples (Figure 7, panel B). This result confirms that the EGFP/rJAK2 chimera had the capacity to function as both an autokinase and an exokinase without the need for explicit cytokine stimulation.

\section{Discussion}

Applications of fluorescent protein technology have made a profound and revolutionary impact in biology [36]. Derivatives of the green fluorescent protein cloned from Aequora victoria have been used extensively in biological research based on the assumption that it does not significantly alter the function of its fusion partner [37, 38]. Yet there are occasional reports of functional changes arising in proteins as a consequence of the relative placement of the GFP fusion partner [39, 40]. When we began this study of EGFP-fused JAK2 chimeras, we noticed a change in the fluorescence intensities of the chimeric fluorescent proteins. Our concern that the presence of the fluorescent fusion partner may have reciprocally altered the properties of the JAK2 domain led us to closely examine other properties of the EGFP/rJAK2 chimeras produced in COS-7 cells. Two important observations, 

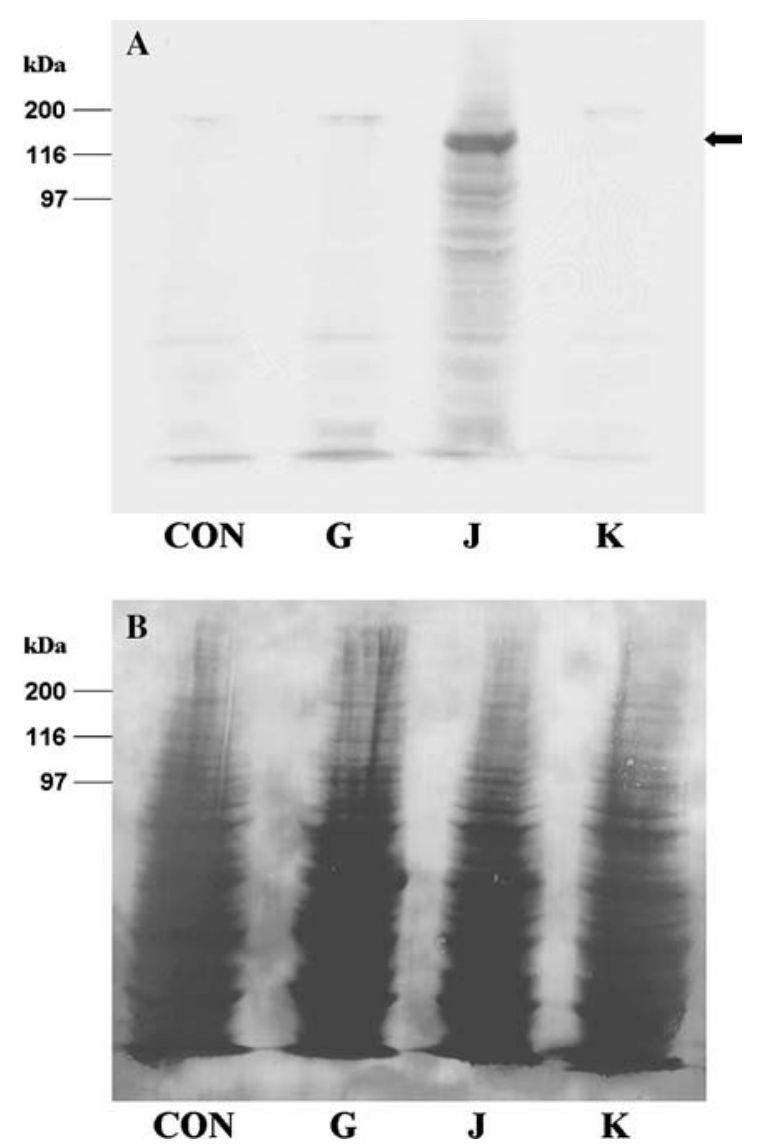

Figure 7. Profile of tyrosine-phosphorylated proteins in COS-7 cells producing various fluorescent proteins. Three days after transient transfection, COS-7 cells were harvested and lysed. The crude lysate components were resolved via SDS-PAGE and transferred to Immobilon-P transfer membrane for Western blot assay. Black arrow points to the EGFP/rJAK2 protein. CON = sham-transfected COS-7 cells; $\mathrm{G}=$ pEGFP-transfectants; $\mathrm{J}=$ pEGFP:rJAK2-transfectants; $\mathrm{K}=$ pEGFP:rJAK2(K882E)-transfectants. Panel A: Western blot analysis using anti-phosphotyrosine antibody. Panel B: Membrane used in panel A was stained with Coomassie Blue R250 to allow general comparison of protein loading in lanes.

which we will now discuss, emerged from the experiments which ensued.

\section{Characteristics of the EGFP/rJAK2 chimeras produced in COS-7 cells}

Western blot analyses using anti-GFP and antiJAK2 antibodies showed that EGFP/rJAK2 and EGFP/rJAK2(K882E) were expressed at approximately equal levels in COS-7 cells, and that the recombinant JAK2 forms were produced at a much higher level than the endogenous JAK2
(Figure 6). Western blot analysis using antiphosphotyrosine antibodies revealed that only EGFP/rJAK2 exhibited significant tyrosine phosphorylation in situ (Figure 6, panel C). We interpret the constitutive activation of EGFP/ rJAK2 as an apparent consequence of overexpression, as its tyrosine autophosphorylation did not require explicit cytokine receptor stimulation. Corroborating evidence for constitutive EGFP/ rJAK2 activation was observed in the in situ transphosphorylation of various cellular proteins (Figure 7, panel A). Although a significant level of in situ tyrosine autophosphorylation was not observed in the endogenous JAK2 protein, it possessed a significantly higher level of normalized in vitro radiolabelling autokinase activity than did the EGFP/rJAK2. The endogenous JAK2 may have contained a sufficient, albeit undetectable, level of tyrosine phosphorylation within the activation loop so that it could efficiently autophosphorylate under in vitro assay conditions [41].

The apparent low level of EGFP/rJAK2's in vitro activity was a surprising result. Typically, the tyrosine phosphorylation status of JAK2 correlates positively with the incorporation of radioactive phosphate in the in vitro radiolabelling autokinase assay. While it is possible that the presence of the EGFP fusion partner may have perturbed the enzymatic properties of the JAK2 domain, we would like to suggest another interpretation. A simple and plausible explanation for our unexpected observation might be that hyperphosphorylation of the chimeric EGFP/rJAK2 in situ resulted in a relative paucity of available free tyrosine sites for subsequent in vitro autophosphorylation. Our laboratory is more rigorously evaluating this explanation for the unexpected discordance between in situ hyperphosphorylation and in vitro hypophosphorylation when certain recombinant JAK2 variants are assayed (Lee, Chatti and Duhe, unpublished results).

\section{Subcellular localizations of EGFP/rJAK2 and $E G F P / r J A K 2(K 882 E)$}

To determine the subcellular distribution of the recombinant proteins, the transiently transfected COS-7 cells were examined via epifluorescence microscopy after DAPI counterstaining. 
Consistently, the EGFP/rJAK2 was ubiquitously distributed throughout the transfected COS-7 cells, as was the case with the non-tagged EGFP (Figure 2). Interestingly, EGFP/rJAK2(K882E) was excluded from the nucleus in some cells, but was uniformly distributed in other transfected cells in the same experiments (compare Figure 2, patterns A vs. B).

These observations are noteworthy because, while various groups employing a variety of approaches to determine the subcellular localization of JAKs have provided apparently conflicting conclusions [16, 18, 20, 21], reports of ubiquitous distribution are rare. To our knowledge, the observation that a single JAK isoform can either be located in or excluded from the nucleus under identical experimental conditions has not been previously reported.

The current controversy surrounding the subcellular localization of JAKs [16, 18, 20, 21, 42, 43] arose in part from differences in experimental methodologies (e.g., immunohistochemistry vs. chimeric fluorescent protein expression) and in reagent selection (e.g., different cell lines). There is a reasonable expectation to find evidence for the membrane localization of JAK2, because as one group correctly stated, "all functional features of JAK proteins point to their involvement in events occurring at the cell surface or at intracellular membranes" [16]. However, one must remain open to other scenarios, as exemplified by the recognition that the epidermal growth factor receptor (EGFR) protein-tyrosine kinase, long established as a transmembrane transducer of extracellular signals, can upregulate cyclin D1 when EGFR is localized to the nucleus [44]. Because a nuclear localization sequence has been identified in JAK2 [20], perhaps the empirical evidence underlying contemporary dogma should be reconsidered. For example, co-immunoprecipitation experiments helped establish the physical association between JAKs and the intracellular domains of cytokine receptors. In those experiments non-ionic detergent solubilization or mechanical disruption was used to lyse the cells, followed by sedimentation of insoluble materials, which would have removed the nuclear components from further examination. Further, one must acknowledge that many, if not most, commercial antibodies recognizing JAK2 will apparently cross-react with other proteins and are hence unsuitable for immunohistochemical studies.
Therefore, the subcellular localization of the chimeric JAK2 should be examined cautiously with multiple methodologies to compensate for artifacts. We employed subcellular fractionation techniques to confirm that the EGFP/rJAK2 chimera was clearly present in membrane, cytosol and nuclear fractions. The EGFP/rJAK2 proteins in all compartments contained phosphorylated tyrosine residues (Figure 3, panel C, lanes 4, 5 and 6; Figure 4, panel C, lanes 1, 2 and 3), including tyrosine phosphorylation within the activation loop (Figure 3, panel D, lanes 4, 5 and 6; Figure 4, panel D, lanes 1, 2 and 3). In contrast, neither the endogenous JAK2 (Figure 3) nor the inactive EGFP/rJAK2(K882E) (Figure 4, panel C and $\mathrm{D}$, lanes 4,5 , and 6 ) exhibited any sign of tyrosine phosphorylation.

We were somewhat surprised that the endogenous JAK2 was so clearly detected in the cytosol and nuclear fractions (Figure 3, panel A, lanes 2, 3, 5 and 6). Endogenous JAK2 could be detected in the membrane fraction when adequate amounts of protein were analyzed (Figure 4, panel A, lanes 1 and 4). Taken together, the results of the subcellular fractionation experiments (Figure 3 and 4) and the microscopy evidence (Figures 1 and 2) indicate that the EGFP/rJAK2 is ubiquitously distributed throughout the transfected COS-7 cells.

The nuclear localization of JAK2, which has been reported with variable consistency from one lab to another, may have physiological significance and should therefore be carefully scrutinized. The signal transduction pathways related to receptor-associated JAK2 activation have been well-characterized and are now accepted as dogma. If JAK2 is exclusively associated with the membrane, then one would expect that overexpression of JAK2 might simply increase classical receptor-associated signal transduction throughput. However, because we have previously noted that JAK2's substrate recognition is promiscuous [15], then we predict that the subcellular distribution of active JAK2 would significantly alter the pattern of JAK2-catalyzed substrate phosphorylation. If it is true that active JAK2 is present in the nucleus under certain conditions, then the resultant pattern of substrate phosphorylation would be radically different from the classical receptorassociated pattern. This may be of particular importance in studying the mechanism of JAK2mediated neoplastic transformation, which is a 
subject of great interest and of many ongoing investigations.

\section{Acknowledgements}

This research was supported by the American Cancer Society (Research Scholar Grant RSG01-060-01-CDD). The authors are grateful to Dr. Marvin Cuchens and Ms. Nancy Harvey for technical support with the FACS experiments and to Dr. Heather Drummond and Dr. Dhananjay Yellajoshyuia for invaluable help with confocal and upright microscopy experiments. We also thank Ms. Kanakadurga Kundrapu, Mr. John K. Smith, Dr. John C. Kermode, Dr. Kiranam Chatti and Dr. Naila M. Mamoon for their helpful suggestions.

\section{References}

1. Harpur A.G., Andres A.C., Ziemiecki A., Aston R.R. and Wilks A.F., JAK2, a third member of the JAK family of protein tyrosine kinases. Oncogene 7: 1347-1353, 1992.

2. Silvennoinen O., Witthuhn B.A., Quelle F.W., Cleveland J.L., Yi T. and Ihle J.N., Structure of the murine Jak2 protein-tyrosine kinase and its role in interleukin 3 signal transduction. Proc. Natl. Acad. Sci. USA 90: 8429-8433, 1993.

3. Rawlings J.S., Rosler K.M. and Harrison D.A., The JAK/ STAT signaling pathway. J. Cell Sci. 117: 1281-1283, 2004.

4. Wilks A.F., Two putative protein-tyrosine kinases identified by application of the polymerase chain reaction. Proc. Natl. Acad. Sci. USA 86: 603-1607, 1989.

5. Johnston J.A., Kawamura M., Kirken R.A., Chen Y.Q., Blake T.B., Shibuya K., Ortaldo J.R., McVicar D.W. and O'Shea J.J., Phosphorylation and activation of the Jak-3 Janus kinase in response to interleukin-2. Nature 370: 151153,1994

6. Witthuhn B.A., Silvennoinen O., Miura O., Lai K.S., Cwik C., Liu E.T. and Ihle J.N., Involvement of the Jak-3 Janus kinase in signalling by interleukins 2 and 4 in lymphoid and myeloid cells. Nature 370: 153-157, 1994.

7. Firmbach-Kraft I., Byers M., Shows T., Dalla-Favera R. and Krolewski J.J., Tyk2, prototype of a novel class of nonreceptor tyrosine kinase genes. Oncogene 5: 1329-1336, 1990.

8. Joos S., Kupper M., Ohl S., von Bonin F., Mechtersheimer G., Bentz M., Marynen P., Moller P., Pfreundschuh M., Trumper L. and Lichter P., Genomic imbalances including amplification of the tyrosine kinase gene JAK2 in CD30+ Hodgkin cells. Cancer Res. 60: 549-552, 2000.

9. Meydan N., Grunberger T., Dadi H., Shahar M., Arpaia E., Lapidot Z., Leeder J.S., Freedman M., Cohen A., Gazit A., Levitzki A. and Roifman C.M., Inhibition of acute lymphoblastic leukemia by a Jak-2 inhibitor. Nature 379: 645-648, 1996.
10. Yoshikawa H., Matsubara K., Qian G.S., Jackson P., Groopman J.D., Manning J.E., Harris C.C. and Herman J.G., SOCS-1, a negative regulator of the JAK/STAT pathway. Nat. Genet. 28: 29-35, 2001.

11. Lacronique V., Boureux A., Valle V.D., Poirel H., Quang C.T., Mauchauffe M., Berthou C., Lessard M., Berger R., Ghysdael J. and Bernard O.A., A TEL-JAK2 fusion protein with constitutive kinase activity in human leukemia. Science 278: 1309-1312, 1997.

12. Peeters P., Raynaud S.D., Cools J., Wlodarska I., Grosgeorge J., Philip P., Monpoux F., Van Rompaey L., Baens M., Vanden Berghe H. and Marynen P., Fusion of TEL, the ETS-variant gene 6 (ETV6), to the receptor-associated kinase JAK2 as a result of $t(9 ; 12)$ in a lymphoid and $t(9 ; 15 ; 12)$ in a myeloid leukemia. Blood 90: 2535-2540, 1997.

13. Neubauer H., Cumano A., Muller M., Wu H., Huffstadt U. and Pfeffer K., Jak2 deficiency defines an essential developmental checkpoint in definitive hematopoiesis. Cell 93: 397-409, 1998.

14. Parganas E., Wang D., Stravopodis D., Topham D.J., Marine J.C., Teglund S., Vanin E.F., Bodner S., Colamonici O.R., van Deursen J.M., Grosveld G. and Ihle J.N., Jak2 is essential for signaling through a variety of cytokine receptors. Cell 93: 385-395, 1998.

15. Duhe R.J, Clark E.A. and Farrar W.L., Characterization of the in vitro kinase activity of a partially purified soluble GST/JAK2 fusion protein. Mol. Cell. Biochem. 236: 23-35, 2002.

16. Behrmann I., Smyczek T., Heinrich P.C., Schmitz-Vande Leur H., Komyod W., Giese B., Muller-Newen G., Haan S. and Haan C., Janus kinase (Jak) subcellular localization revisited: the exclusive membrane localization of endogenous Janus kinase 1 by cytokine receptor interaction uncovers the Jak receptor complex to be equivalent to a receptor tyrosine kinase. J. Biol. Chem. 279: 35486-35493, 2004.

17. Giese B., Au-Yeung C.K., Herrmann A., Diefenbach S., Haan C., Kuster A., Wortmann S.B., Roderburg C., Heinrich P.C., Behrmann I. and Muller-Newen G., Long term association of the cytokine receptor gp130 and the Janus Kinase Jak1 revealed by FRAP analysis. J. Biol. Chem. 278: 39205-39213, 2003.

18. Ito M., Nakasato M., Suzuki T., Sakai S., Nagata M. and Aoki F., Localization of janus kinase 2 to the nuclei of mature oocytes and early cleavage stage mouse embryos. Biol. Reprod. 71: 89-96, 2004.

19. Ram P.A. and Waxman D.J., Interaction of growth hormone-activated STATs with SH2-containing phosphotyrosine phosphatase SHP-1 and nuclear JAK2 tyrosine kinase. J. Biol. Chem. 272: 17694-17702, 1997.

20. Lobie P.E., Ronsin B., Silvennoinen O., Haldosen L.A., Norstedt G. and Morel G., Constitutive nuclear localization of Janus kinases 1 and 2. Endocrinology 137: 40374045, 1996.

21. Moulin S., Bouzinba-Segard H., Kelly P.A. and Finidori J., Subcellular trafficking of growth hormone receptor and Jak2 under ligand exposure. Horm. Metab. Res. 35: 396401, 2003.

22. Tsien R.Y., The green fluorescent protein. Annu. Rev. Biochem. 67: 509-544, 1998.

23. Duhe R.J., Rui H., Greenwood J.D., Garvey K. and Farrar W.L., Cloning of the gene encoding rat JAK2, a protein tyrosine kinase. Gene 158: 281-285, 1995. 
24. Rui H., Kirken R.A. and Farrar W.L., Activation of receptor-associated tyrosine kinase JAK2 by prolactin. J. Biol. Chem. 269: 5364-5368, 1994.

25. Duhe R.J., Evans G.A., Erwin R.A., Kirken R.A., Cox G.W. and Farrar W.L., Nitric oxide and thiol redox regulation of Janus kinase activity. Proc. Natl. Acad. Sci. USA 95: 126-131, 1998

26. Buckley A.R., Crowe P.D. and Russell D.H., Rapid activation of protein kinase $\mathrm{C}$ in isolated rat liver nuclei by prolactin, a known hepatic mitogen. Proc. Natl. Acad. Sci. USA 85: 8649-8653, 1988.

27. Feng J., Witthuhn B.A., Matsuda T., Kohlhuber F., Kerr I.M. and Ihle J.N., Activation of Jak2 catalytic activity requires phosphorylation of Y1007 in the kinase activation loop. Mol. Cell. Biol. 17: 2497-2501, 1997.

28. Rui L., Gunter D.R., Herrington J. and Carter-Su C., Differential binding to and regulation of JAK2 by the $\mathrm{SH} 2$ domain and N-terminal region of SH2-b-beta. Mol. Cell. Biol. 20: 3168-3177, 2000.

29. Tjoelker L.W., Seyfried C.E., Eddy R.L. Jr., Byers M.G., Shows T.B., Calderon J., Schreiber R.B. and Gray P.W., Human, mouse, and rat calnexin cDNA cloning: identification of potential calcium binding motifs and gene localization to human chromosome 5. Biochemistry 33: 3229-3236, 1994.

30. Lee I., Kim M.K., Choi E.Y., Mehl A., Jung K.C., Gil M.C., Rowe M. and Park S.H., CD99 expression is positively regulated by $\mathrm{Sp} 1$ and is negatively regulated by Epstein-Barr virus latent membrane protein 1 through nuclear factor-kappa B. Blood 97: 3596-3604, 2001.

31. McKeon F.D., Kirschner M.W. and Caput D., Homologies in both primary and secondary structure between nuclear envelope and intermediate filament proteins. Nature 319: 463-468, 1986.

32. Fisher D.Z., Chaudhary N. and Blobel G., cDNA sequencing of nuclear lamins $\mathrm{A}$ and $\mathrm{C}$ reveals primary and secondary structural homology to intermediate filament proteins. Proc. Natl. Acad. Sci. USA 83: 6450-6454, 1986.

33. Sefton B.M., Hunter T. and Beemon K., Product of in vitro translation of the Rous sarcoma virus $s r c$ gene has protein kinase activity. J. Virol. 30: 311-318, 1979.

34. Hunter T. and Sefton B.M., Transforming gene product of Rous sarcoma virus phosphorylates tyrosine. Proc. Natl. Acad. Sci. USA 77: 1311-1315, 1980.
35. Witte O.N., Dasgupta A. and Baltimore D., Abelson murine leukemia virus protein is phosphorylated in vitro to form phosphotyrosine. Nature 283: 826-831, 1980.

36. Hadjantonakis A.K., Dickinson M.E., Fraser S.E. and Papaioannou V.E., Technicolour transgenics: imaging tools for functional genomics in the mouse. Nat. Rev. Genet. 4: 613-625, 2003.

37. Cubitt A.B., Heim R., Adams S.R., Boyd A.E., Gross L.A. and Tsien R.Y., Understanding, improving and using green fluorescent proteins. Trend Biochem. Sci. 20: 448-455, 1995.

38. Chiesa A., Rapizzi E., Tosello V., Pinton P., de Virgilio M., Fogarty K.E. and Rizzuto R., Recombinant aequorin and green fluorescent protein as valuable tools in the study of cell signaling. Biochem. J. 355: 1-12, 2001.

39. Wittenmayer N., Rothkegel M., Jockusch B.M. and Schluter K., Functional characterization of green fluorescent protein-profilin fusion proteins. Eur. J. Biochem. 267 : 5247-5256, 2000.

40. Ketteler R., Heinrich A.C., Offe J.K., Becker V., Cohen J., Neumann D. and Klingmuller U., A functional green fluorescent protein-tagged erythropoietin receptor despite physical separation of JAK2 binding site and tyrosine residues. J. Biol. Chem. 277: 26549-26522, 2002.

41. Chatti K., Farrar W.L. and Duhe R.J., Tyrosine phosphorylation of the Janus kinase 2 activation loop is essential for a high-activity catalytic state but dispensable for a basal catalytic state. Biochemistry 43: 4272-4283, 2004.

42. Sorenson R.L. and Stout L.E., Prolactin receptors and JAK2 in islets of Langerhans: an immunohistochemical analysis. Endocrinology 136: 4092-4098, 1995.

43. Ragimbeau J., Dondi E., Vasserot A., Romero P., Uzé G. and Pellegrini S., The receptor interaction region of Tyk2 contains a motif required for its nuclear localization. J. Biol. Chem. 276: 30812-30818, 2001.

44. Lin S.-Y., Makino K., Xia W., Matin A., Wen Y., Kwong K.Y., Bourguignon L. and Hung M.-C., Nuclear localization of EGF receptor and its potential new role as a transcription factor. Nat. Cell Biol. 3: 802-808, 2001. 